costs were for stationery, photocopying, postage and follow-up telephone calls.

The main weakness of the design is the lack of evidence for reliability for the questions asked. Inevitably, those people who, for whatever reason, do not attend the service as currently configured could not contribute to the feedback process. The strengths of the survey method are the simplicity and face validity of the design and the rapid recruitment of 100 broadly representative service users (Gossop et al, 1998). Their anonymous ratings may give a clearer understanding of their perspective than solicited feedback from a small number of individuals for 360-degree appraisal or a suggestions box. The results provided valuable positive feedback to staff, and were useful for discussion of the overall direction of the service, indicating areas that need improvement.

Most patients wanted to express their views about service improvement, but the failure to identify any patient who was willing to take any more active part in service planning is disappointing. This seems to be a recognised limitation of such an exercise (Coulter, 2002).

In response to the findings the Specialist Community Addiction Services are developing a range of information leaflets. This is one of the key policies recommended by the National Treatment Agency (2002). The desirability of changes to the décor of waiting areas and consulting rooms has been fed through to relevant management groups. Reducing waiting times and making the waiting and consulting rooms welcoming play a big part in engaging the patient in treatment.

\section{Declaration of interest}

None.

original papers

\section{References}

AUDIT COMMISSION (2002) Changing Habits: The Commissioning and Management of Community Drug Treatment Services for Adults. Audit Commission.

COULTER, A. (2002) Involving patients: representation or representativeness? Health Expectations, 5, 1

DEPARTMENT OF HEALTH (2004) Patient and Public Involvement in Health: The Evidence for Policy Implementation. Department of Health

FOUNTAIN, J., GRIFFITHS, P., STRANG J., et al (2000) Measuring met and unmet need of drug misusers: integration of quantitative and qualitative data. European Addiction Research, 6,97-103.

GOSSOP, M., MARSDEN, J. \& STEWART, D. (1998) NTORS at One Year: The National Treatment Outcome Research
Study - Changes in Substance Use, Health and Criminal Behaviours One Year after Intake. Department of Health

KAY, R.W. \& PETERS, A. D. (1992) A pilot survey of client opinion of the Lothian Community Drug Problem Service: likes, dislikes, efficacy and improvements. Health Bulletin, 50, 32-38.

MARSHALL, G. N. \& HAYS, R. D. (1994) Health Survey - Patient Satisfaction Questionnaire - PSQ 18. The Patient Satisfaction Questionnaire Short-Form (PSQ-18). RAND Corporation.

\section{NATIONAL TREATMENT AGENCY}

(2002) Models of Care for the

Treatment of Adult Drug Misusers. NTA.

WORLD HEALTH ORGANIZATION (2000) Client Satisfaction Evaluation. Workbook 6. WHO.

*Palanivelu S. Kumar Specialist Registrar and Lecturer, Department of Psychiatry, University of Hull, Hertford Building, Cottingham Road, Hull HU6 7RX, email: drpskumar@doctors.org.uk, Andrew McBride Consultant Psychiatrist, Specialist CommunityAddictions Service, The Rectory Centre, Rectory Road, Oxford OX4 1BU

\title{
Working with adults with personality disorder in the community: a multi-agency interview study
}

\author{
AIMS AND METHOD \\ To explore the impact of adults with \\ personality disorder on the profes- \\ sional groups that support them. \\ Staff ( $n=72)$ from five agencies par- \\ ticipated in interviews focusing on \\ reactions to short case vignettes \\ representing the three personality \\ disorder clusters.
}

\author{
RESULTS \\ Each presentation was relatively con- \\ sistent in its impact on staff irrespec- \\ tive of the agency or setting. Several \\ agency-specific themes were also \\ identified, some illustrating areas of \\ potential difficulty in inter-agency \\ working. Many non-mental health \\ workers reported considerable \\ contact with this client group,
}

\begin{abstract}
although most felt dissatisfied with the training available and suggested solutions.

\section{CLINICAL IMPLICATIONS}

Findings from this study may help to match the content of training courses to need. Similar vignette-based surveys could be used to investigate the impact of staff training over time.
\end{abstract}

The importance of a multi-agency perspective when planning care for people with personality disorder is now widely accepted, particularly since many of those affected will be excluded from mainstream services (National Institute for Mental Health in England, $2003 a, b)$. However, although there is no shortage of evidence for such exclusion, there have been few systematic investigations of the impact of adults with personality disorder on professional groups not primarily involved with healthcare. A particular methodological difficulty is that personality disorder is a poorly defined concept for many people working outside mental health settings. This qualitative study sought to remedy this deficit by interviewing a sample of staff from relevant agencies within and outside mental health settings. The need to explain what was meant by the term 'personality 
disorder' was circumvented by presenting vignettes representing prototypic examples from the three original personality disorder clusters to each interviewee. papers

\section{Method}

Interviews were held with a sample of staff likely to have experience of working with adults with personality disorder. Volunteers were recruited from five agencies (mental health, housing, accident and emergency (A\&E) departments, probation and social services) across the East Midlands. The catchment area for this study encompassed a mix of urban and rural settings across four counties with a total population 3.54 million, including three cities with populations greater than 220000 (2001 Census). Additional requests for participants were issued in an attempt to balance the number of volunteers from each agency wherever the initial response appeared weak. The study was approved by the relevant research ethics committees and all participants gave their written consent.

Three short hypothetical vignettes were prepared to represent individuals likely to meet the DSM-IV criteria for personality disorder within Clusters A, B and C respectively (American Psychiatric Association, 1994), although none contained reference to any diagnosis. Male and female versions of each vignette were constructed. The Cluster A vignette was strongly suggestive of paranoid personality disorder, the Cluster B vignette of antisocial personality disorder with borderline traits and the Cluster C vignette of dependent personality disorder with avoidant traits (vignettes available from N.H. on request). Each vignette was less than 170 words and the amount of

Table 1. Characteristics of 72 interviewees

\begin{tabular}{|c|c|c|}
\hline & $n$ & $\%$ \\
\hline \multicolumn{3}{|l|}{ Gender } \\
\hline Male & 30 & 42 \\
\hline Female & 42 & 58 \\
\hline \multicolumn{3}{|l|}{ Agency } \\
\hline Mental health service & 19 & 26 \\
\hline Housing service & 22 & 31 \\
\hline Probation service & 12 & 17 \\
\hline A\&E department & 9 & 12 \\
\hline Social worker/social services & 10 & 14 \\
\hline \multicolumn{3}{|l|}{ Training in mental health issues } \\
\hline No training & 7 & 10 \\
\hline Less than 7 training days & 37 & 51 \\
\hline 7 or more training days & 28 & 39 \\
\hline \multicolumn{3}{|l|}{ Experience working in current agency } \\
\hline Less than 3 years & 7 & 10 \\
\hline $3-8$ years & 25 & 35 \\
\hline More than 8 years & 39 & 54 \\
\hline Currently a middle or senior manager & 30 & 42 \\
\hline
\end{tabular}

$A \& E$, accident and emergency. information included was deliberately restricted to encourage respondents to draw inferences based on their pre-existing attitudes (Lewis \& Appleby, 1988).

Interviewees considered each vignette in turn as part of a semi-structured interview lasting typically $1 \mathrm{~h}$. Each interviewee was asked the same series of closed and open-ended questions about each presentation to explore how they anticipated the experience of working with the client, with colleagues and with workers in other agencies.

Anonymised transcripts of interviews were obtained either from audiotapes recorded with the interviewee's consent, or from hand-written notes made by the interviewer. The content of each transcript was analysed with the help of a computer program (QSR NUD*IST v4.0) following the main steps in grounded theory. Use of the constant comparative method (Strauss \& Corbin, 1990) allowed substantive codes to be assigned to key themes.

\section{Results}

Seventy-two interviews were conducted between April 2002 and May 2004. Taking the catchment area as a whole, initial requests for participants led to broadly similar response rates from each of the five agencies. However, this response varied geographically and over time (irrespective of agency) and led to additional requests being issued in an attempt to obtain a

Box 1. The six themes most frequently identified in interview transcripts for each presentation

Cluster A presentation (paranoid)

Anticipated as likely to:

- be difficult to engage

- attend appointments irregularly

- be hypersensitive to any change in keyworker

- be unsuitable for group work

- consume disproportionate amounts of staff time

- have potential to exhibit anger and aggression.

Cluster B presentation (antisocial with borderline traits) Anticipated as likely to:

- be more difficult to work with than other two presentations

- consume disproportionate amounts of staff time by making unrealistic demands

- attend appointments irregularly

- have a strong personal impact on staff

- upset other clients

- raise issues of risk and safety (both to self and others)

Cluster C presentation (dependent with avoidant traits) Anticipated as likely to:

- be the least difficult to work with of the three presentations

- raise the least number of potential issues

- raise problems if they became dependent on a member of staff

- present predominantly with Axis I symptoms

- have crisis presentations that encourage prescription of medication that is ultimately unhelpful

- present in a way that all physical symptoms are viewed as psychosomatic 
representative balance in the overall sample. Sample characteristics are summarised in Table 1. Out of the 72 interviewees, 63 made at least one comment, which suggested that the vignettes were relevant to a subset of the clients with whom they were professionally involved. Box 1 summarises the six themes that were most frequently coded for each presentation from all transcripts. Except where stated otherwise, each appeared relatively insensitive to location, agency, gender of interviewee, or gender of vignette presented.

\section{Agency-specific themes}

For the Cluster A vignette, two additional themes emerged consistently in the codings from interviews with housing workers. Housing staff felt particularly familiar with this (paranoid) type of presentation, and felt that many such clients neither sought nor welcomed treatment. For the Cluster B vignette, a theme frequently coded in interviews with A\&E staff was that such (antisocial/borderline) individuals often became impatient and tended to cause the most problems when they were forced to wait for assessment or treatment. Probation staff appeared to experience less anxiety over antisocial presentations in comparison with other interviewees. Mental health staff frequently reported that workers in other agencies tended to expect some immediate and effective action from a psychiatrist or the community mental health team whenever this type of client hit a crisis. For the Cluster $C$ vignette, an additional theme coded frequently in interviews with social workers and housing staff was that this type of client often needed (and would benefit from) home visits, which some agencies would be unable to offer.

Several agency-specific themes were coded frequently and irrespective of the vignette presented. Housing staff commented that they were often the only workers left in contact with a client after all other agencies had withdrawn, and so had needed to find their own ways of supporting such tenants. Mental health staff involved in delivering psychological interventions tended to favour a 'single therapist' model. They valued having a psychiatrist as a central coordinator but not also in the role of therapist, and clients having their care arrangements stated unambiguously and in writing. Staff from A\&E departments felt that their service tended to experience suspicious or dependent presentations as relatively straightforward.

original papers

\section{Potential for disagreement among staff}

Views about the potential for each client to cause disagreement among colleagues are summarised in Table 2. The Cluster B client was considered most likely to give rise to disagreement among those involved. The two lines of cleavage most commonly reported centred on whether the client's condition was treatable (or not) and whether they should engage with the service (or vice versa). The most commonly expressed reason for disagreement about the Cluster A client was whether they had a mental illness or a personality disorder and hence what treatment was most appropriate, and for the Cluster C client whether input would increase social skills or create more dependency.

\section{Training and support}

Interviewees' ratings of the overall level of support and training available to workers in their own agency are presented in Table 2 . Responses to open-ended questions revealed that the majority (but not all) of those interviewed felt supported by their colleagues. Staff in A\&E departments in particular reported a strong sense of working together as a team and supporting each other when difficult patients presented. Descriptions of poor support and inadequate supervision most commonly occurred in the context of the Cluster B presentation.

In contrast, most interviewees were dissatisfied with the training available to them, particularly in relation to the Cluster A and B presentations. The most common complaint was that an organisation had provided training in basic skills to deal with specific behaviour problems (such as anger and aggression) but this had not afforded any deeper understanding of the nature of personality disorder or how best to relate to such a client. The solutions most commonly suggested can be summarised as a desire for pragmatic, scenario-based training to complement more conventional approaches. Staff working

Table 2. Views of interviewees on potential for disagreement among staff in own agency and adequacy of training and support

\begin{tabular}{|lccc} 
& \multicolumn{3}{c}{ Vignette } \\
\cline { 2 - 4 } & $\begin{array}{c}\text { Cluster B } \\
\text { (paranoid) }\end{array}$ & $\begin{array}{c}\text { Cluster C } \\
\text { (antisocial with } \\
\text { borderline traits) }\end{array}$ & $\begin{array}{c}\text { (dependent with } \\
\text { avoidant traits) }\end{array}$ \\
\hline $\begin{array}{l}\text { Potential for disagreement, } n(\%) \\
\text { Likely to cause disagreement }\end{array}$ & $28(41)$ & $54(76)$ & $15(26)$ \\
Unlikely to cause disagreement & $39(57)$ & $14(20)$ & $35(62)$ \\
Don't know & $1(2)$ & $3(4)$ & $7(12)$ \\
Training and support, $n(\%)$ & $15(23)$ & $14(20)$ & $36(65)$ \\
Adequate & $22(32)$ & $26(37)$ & $11(20)$ \\
Less than adequate & $31(45)$ & $31(43)$ & $8(15)$ \\
Poor & & & \\
\hline
\end{tabular}


Box 2. The 13 themes most frequently coded from transcripts in relation to inter-agency working

original

papers

\section{Communication}

- Enhanced when inter-agency communication actively promoted by senior manager

- Enhanced when staff able to contact each other regularly (individually or at meetings)

- Enhanced when staff allow themselves to be reasonably contactable

- Enhanced when agreement between agencies about how confidentiality issues are handled.

\section{Agency role}

- Impaired when poor role definition results in clients falling between many services and getting attention from none

- Enhanced (/impaired) when agency's well-defined role effectively includes (/excludes) such clients.

\section{Individual staff characteristics}

- Enhanced when individual workers agree with policies adopted by their own agency

- Enhanced when individual workers personally favour a multi-agency approach

- Impaired when the most helpful staff end up dealing with most of the incoming enquiries and so get overloaded.

\section{Service provision/accessibility}

- Enhanced if psychological treatments more available to this client group

- Impaired by the current deficit in anger management courses

- Impaired by current lack of alternative to acute ward admission or reliable out-of-hours services when clients hit crisis

- Impaired when specialist services 'cherry pick' the better therapeutic prospects.

1. The terms 'enhanced' and 'impaired' were applied in the context of impact on inter-agency working.

outside mental health settings tended to value being taught by someone who managed this client group on a day-to-day basis and who could bring specific examples to illustrate real-life situations. Some mental health professionals were not always considered suitable for this role, however. The reason most often given was that they rarely met their clients outside a clinical setting and thus were seen as too far removed from handling real-life situations face to face.

\section{Inter-agency working}

The 13 most frequently coded themes relating to interagency working fell within four categories (communication, agency role, individual staff characteristics and service provision/accessibility) (Box 2). An additional and frequently coded theme (not easily classified into one of the four categories) was that the perception that interagency working had improved significantly since the advent of 'joined up' primary care teams. Views about the value of having a clearly defined agency role were notably inconsistent. This was exemplified when the probation service was praised for having clear boundaries but then criticised for not making its treatment groups available to non-probation clients.

A number of agency-specific themes also emerged. Housing workers generally regarded the probation service and the police as helpful, but were critical of mental health staff when patients were discharged from wards before accommodation was available, and when community nursing support was withdrawn once a client was considered to have 'settled'. Housing workers found themselves invited to care programme approach meetings only rarely, but felt this would be invaluable in some cases. Mental health staff reported difficulties working with housing and crisis services if their workers did not respect or understand their treatment model or gave 'advice' to patients that clashed with that model. Staff in A\&E departments tended to welcome the input they received from police and from local self-harm/liaison teams where these existed, but some remained critical of delays in obtaining psychiatric assessments. Probation staff reported good links with housing workers, but were critical of mental health staff for inconsistency in their clinical assessments and for their occasional unwillingness to share information on the grounds of confidentiality.

\section{Discussion}

Although this was a small study carried out over a limited geographical area and with a self-selecting sample, our findings suggest that brief vignettes are effective in eliciting relevant data. The study has identified a number of important issues that will be relevant to many agencies whose staff work with clients with personality disorder. Knowledge of these issues - including those that emerged as agency-specific - is likely to be helpful when planning staff training programmes.

The Cluster B presentation was most likely to lead to disagreement among colleagues. It was also the presentation that workers felt least adequately trained to manage and the one that raised the greatest number of potential difficulties. This is in keeping with a report by Rigby \& Longford (2004) on the experience of running a multi-agency training course on personality disorder. They noted that each time their trainees were asked to construct a vignette of a client with personality disorder they did so using borderline presentations based on the clients who caused the greatest problems.

Interestingly, the majority of commonly identified themes in the interviews reported here emerged as vignette-specific but not agency-specific. It has been suggested that one reason why clients with personality disorder create so many problems in treatment is that they evoke inconsistency (Bateman \& Tyrer, 2004). Although this is to some extent supported by the apparent ability of the Cluster B presentation in particular to cause disagreement within a team, our findings suggest that certain personality disorder presentations were relatively consistent in their impact on staff irrespective of the agency in which they worked. 
A minority of themes emerged as exclusive to a particular agency. The perception among many housing workers that they were often left to support a client with personality disorder after all other agencies had withdrawn seems particularly significant and, in our experience, not often considered by mental health professionals. Similar views are reported in a recent survey of housing staff in South Yorkshire and North Lincolnshire (National Institute for Mental Health in England, 2006) which concluded that the majority of mainstream or 'general needs' housing staff saw themselves as providing a significant and valuable but often unsung role in community mental healthcare.

We concluded that the interviewees from agencies other than mental health had considerable experience of working with clients likely to have personality disorder. Furthermore, most appeared to have accepted that regular contact with such clients was necessary in their work. Their comments suggested many had drawn on (and refined) their existing skills to a point where they generally considered themselves to be reasonably competent in dealing with this client group. However, the vast majority felt they lacked greater understanding and were dissatisfied with the paucity of relevant training. The document Breaking the Cycle of Rejection (National Institute for Mental Health in England, 2003b) acknowledged the very limited availability of such training for staff working in generic, community-based services, and offered a framework within this could be addressed. Our findings support this but also suggest the need to match any new training to deficits, so that new courses can include specific content relevant to the staff group being taught. The vignette-based approach described here might be particularly valuable when attempting to identify such deficits, and when trying to quantify the impact of staff training over time.

\section{Declaration of interest}

None. Funding detailed in Acknowledgements.

original

papers

\section{Acknowledgements}

This study was funded by the National Programme for Forensic Mental Health R\&D and the Home Office. We thank Marianna Perdikouri and Helen Bourne for their help with administration and transcription, and all those who volunteered to be interviewed for their co-operation and time.

\section{References}

AMERICAN PSYCHIATRIC the Cycle of Rejection: The Personality ASSOCIATION (1994) Diagnostic and Statistical Manual of Mental Disorders (4th edn) (DSM-IV). APA.

BATEMAN, A. W. \& TYRER, P. (2004)

Services for personality disorder: organisation for inclusion. Advances in Psychiatric Treatment, 10, 425-433.

LEWIS, G. \& APPLEBY, L. (1988)

Personality disorder: the patients psychiatrists dislike. British Journal of Psychiatry, 153, 44-49. Disorder Capabilities Framework. Department of Health. NATIONAL INSTITUTE FOR MENTAL HEALTH IN ENGLAND (2006) At Home? A Study of Mental Health Issues Arising in Social Housing. http:// www.socialinclusion.org.uk/ publications / GNHFullReport.doc

RIGBY, M. \& LONGFORD, J. (2004) Development of a multi-agency experiential training course on NATIONAL INSTITUTE FOR MENTAL_personality disorder. Psychiatric HEALTH IN ENGLAND (2003a) Personality Disorder: No Longer a Diagnosis of Exclusion. Department of Health. Bulletin, 28, 337-341.

\section{STRAUSS, A. \& CORBIN, J. (1990) Basics}

of Qualitative Research: Grounded Theory Procedures and Techniques.

NATIONAL INSTITUTE FOR MENTAL Sage.

HEALTH IN ENGLAND (2003b) Breaking

*Nick Huband Clinical Research Fellow, Section of Forensic Mental Health, University of Nottingham and Nottinghamshire Healthcare NHS Trust, Duncan Macmillan House, Porchester Road, Nottingham NG36AA, email: nick.huband@nottshc.nhs.uk, Conor Duggan Professor and Head, Section of Forensic Mental Health, University of Nottingham, Nottingham 